\title{
Caracterização de lodo ativado e lodo físico-químico de estação de tratamento de efluentes de indústrias de arroz parboilizado e de laticínios para geração de energia térmica
}

\section{Alberto Kuhn Klumb, Ricardo Lemos Sainz*}

\author{
Instituto Federal Sul-Rio-Grandense. Campus Pelotas. Praça Vinte de Setembro, \\ 455. Centro. Pelotas-RS, Brasil (CEP 96015-360). *E-mail: \\ ricardosainz@pelotas.ifsul.edu.br.
}

Resumo. Os lodos gerados em Estação de Tratamento de Efluentes (ETE) são considerados resíduos sólidos e possuem em sua composição elementos como carbono, hidrogênio, enxofre, oxigênio e nitrogênio onde, através da oxidação destes, há uma reação exotérmica capaz de gerar calor. 0 presente trabalho teve como objetivo caracterizar lodos de ETE de uma indústria de laticínios (LA01) e de duas indústrias de arroz parboilizado (AR01 e AR02), prevendo o seu uso para queima em caldeira. Foram determinados de umidade, teores de combustíveis e de cinzas, carbono orgânico, nitrogênio, enxofre, hidrogênio, oxigênio e poder calorífico superior e inferior. Os resultados indicam que os três tipos de lodo têm umidades semelhantes. 0 lodo LA01 possui maior quantidade de combustíveis, em comparação às amostras AR01 e AR02 e às biomassas mais utilizadas nas indústrias (lenha e casca de arroz). As amostras de lodo de ETE de arroz parboilizado possuem maior quantidade de cinzas que a de laticínios. Os três tipos de lodo estudados possuem nitrogênio e enxofre em concentrações menores do que lodos de esgoto sanitário, o que é uma vantagem, devido a menor emissão de NOx e SOx. O balanço de energia realizado propõe que os lodos LA01 e AR01 possuem conteúdo de energia residual positivo, enquanto no lodo LA02 é negativo. 0 uso destes lodos em processo de combustão para geração de energia térmica também é atrativo devido à diminuição dos custos logísticos de destinação dos mesmos para disposição em solo.

Palavras-chave: Método térmico; Conteúdo energético; Valorização de resíduos; Biomassa; Combustível alternativo.

Abstract. Characterization of activated and physicalchemichal sludge of Wastewater Treatment Plant of parboiled rice and dairy industries from thermal energy generation. The sludge of Wastewater Treatment Plant (WWTP) are considered as solid waste and have in their composition elements such as carbon, hydrogen, sulfur, oxygen and nitrogen witch, through oxidation of these elements, there is an exothermic reaction
Recebido:

03/04/2018

Aceito:

09/07/2018

Publicado:

$31 / 08 / 2018$

Acesso aberto

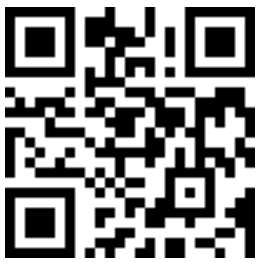

ORCID

(D) 0000-0003-1951-2439 Alberto Kuhn Klumb

(D) 0000-0001-9338-7993

Ricardo Lemos Sainz 
capable of generate heat (energy) that can be used for a thermal system (boiler). This study aimed to characterize sludge WWTP of a dairy industry (LA01) and two parboiled rice industries (AR01 and AR02), providing its use for burning in boiler. It were performed moisture analyzes, fuel levels and ash, organic carbon, nitrogen, sulfur, hydrogen, oxygen and higher and lower calorific value. The results indicate that the three kinds of sludge have similar moisture contents. The LA01 sludge has higher amount of fuel compared to AR01 and AR02 samples and biomass more used in industries (wood and rice husk). Samples of parboiled rice WWTP sludge have a greater amount of ash that the dairy one. The three kinds of studied sludge have nitrogen and sulfur in lower concentration than sewage sludge and this is an advantage, because it will generate lower emissions of NOx and SOx. The energy balance suggests that the LA01 and AR01 sludge have positive residual energy content, while in the LA02 sludge is negative. The use of the sludge in combustion process of thermal power generation is also attractive due to reduction of logistics costs of allocation of them to soil disposal.

Keywords: Thermal method; Energy content; Waste recovery; Biomass; Alternative fuel.

\section{Introdução}

Dentre os destinos finais de lodo de ETE mais praticados pelas indústrias, atualmente, encontram-se a aplicação como fertilizante em solo agrícola e disposição em aterros sanitários (Werther e Ogada, 1999).

Como a Lei no 12.305/2010, prevê a utilização de aterros sanitários somente para os rejeitos, alguns objetivos devem ser alcançados, dentre eles a reutilização e a reciclagem dos resíduos sólidos. Além disso, está previsto pela Política Nacional de Resíduos Sólidos o incentivo ao desenvolvimento de sistemas de gestão ambiental e empresarial voltados para a melhoria dos processos produtivos e ao reaproveitamento dos resíduos sólidos, incluídos a recuperação e o aproveitamento energético (Brasil, 2010).

As biomassas mais utilizadas para aproveitamento energético no Brasil são a cana de açúcar, lenha, biogás, licor negro (indústrias de celulose e papel), carvão vegetal, óleo vegetal e cascas de arroz (Silva et al., 2016). Os lodos de ETE estão sendo estudados como biomassa alternativa na co-geração de energia, porém o emprego dos mesmos ainda não está popularizado (Borges et al., 2008).

No cenário atual de geração de energia, o uso de biomassa apresenta muitas vantagens, como neutralização as emissões de gases de efeito estufa, baixas emissões de NOx e SOx, competitiva economicamente com os combustíveis fósseis tradicionalmente utilizados e por tratar-se de recursos renováveis (García et al., 2012).

Os métodos de tratamento térmico para lodos de estações de tratamento de efluentes incluem a combustão direta em plantas de incineração, gaseificação e pirólise. No momento, a tecnologia mais promissora de valorização térmica para os lodos é a combustão direta em caldeiras de leito fluidizado à pressão atmosférica (Fytilli e Zabaniotou, 2008; Murakami et al., 2009).

A composição elementar de combustível é uma das mais importantes caracaterísticas destes materiais e é determinada por elementos da fase orgânica (tais como carbono, hidrogênio, 
oxigênio, enxofre e nitrogênio) e da fase inorgânica (cinzas, que podem ser formadas por sílica, alumínio, ferro, cálcio, magnésio, fósforo, entre outros). Os percentuais de nitrogênio e enxofre indicam o impacto do uso de combustível de biomassa, enquanto carbono e hidrogênio permitem a previsão e determinação do poder calorífico teórico de combustão deste combustível em sistemas de termoconversão de energia (Dermimbas, 2003; Khan et al., 2009).

0 calor de combustão, ou poder calorífico, é uma das mais importantes características para determinar o conteúdo de energia no combustível, e ele é determinado por bomba calorimétrica ou calculado por um modelo empírico, e pode ser definido com respeito a duas diferentes referências, o poder calorífico superior (PCS) e o poder calorífico inferior (PCI) (Shi et al., 2016).

Este artigo tem como objetivo caracterizar três tipos de lodo de estação de tratamento de efluentes industriais (ETE), sendo misturas de lodo biológico e físico-químico de uma indústria de laticínios e duas de arroz parboilizado e, também, verificar o balanço de energia resultante da queima dos mesmos avaliando a viabilidade do seu uso para geração de energia térmica em caldeira de leito fluidizado.

\section{Metodologia}

\section{Coleta de amostras}

Foram utilizados lodos de estações de tratamento de efluentes (ETE) de agroindústrias da região sul do Rio Grande do Sul, especificamente de laticínios e de parboilização de arroz, das cidades de Pelotas, Capão do Leão e Rio Grande.

As coletas foram realizadas no mês de agosto de 2015, em tanques de armazenamento de lodo presentes nas três indústrias, conforme normas de amostragem contidas na NBR 10.007:2004 (ABNT, 2004).
O lodo da indústria de laticínios é proveniente da mistura entre o lodo de tratamento físico-químico (primário remoção de material flotado) e biológico (secundário - lodo ativado). 0 lodo das indústrias de parboilização de arroz são provenientes da mistura entre o lodo do tratamento biológico (secundário - lodo ativado) e físico-químico (terciário remoção de fósforo). 0 que diferencia as duas indústrias de arroz parboilizado é o sal inorgânico que cada uma utiliza para precipitação de fósforo (sulfato de alumínio ou carbonato de cálcio). 0 lodo da indústria de laticínios será denominado de LA01 e o das indústrias de arroz parboilizado serão denominados AR01 e AR02, sendo que a primeira indústria utiliza sulfato de alumínio e a segunda utiliza carbonato de cálcio na precipitação do fósforo do efluente.

\section{dos lodos \\ Caracterização físico-química}

As amostras de lodo provenientes das estações de tratamento foram secas em estufa entre $103{ }^{\circ} \mathrm{C}-105^{\circ} \mathrm{C}$ até peso constante para a sequência da caracterização físico-química. A umidade e os teores de sólidos voláteis e fixos foram feitos conforme APHA (2012).

As análises de carbono orgânico total foram realizadas conforme métodos descritos/adaptados por Jimenéz e García (1992), através de calcinação por perda de voláteis em mufla e utilização do fator de 1,8 para a conversão para carbono orgânico total, utilizando a temperatura de $550{ }^{\circ} \mathrm{C}$. A Equação 01 mostra a conversão realizada.

\section{$\mathrm{SV}=\mathrm{C} \times 1,8 \quad$ (Equação 01)}

Onde:

SV = concentração de sólidos voláteis, após secagem a $103-105^{\circ} \mathrm{C}$ e calcinação a $550^{\circ} \mathrm{C}(\%)$

$\mathrm{C}=$ concentração de carbono orgânico total nas amostras (\%)

1,8 = fator de conversão 
As análises elementares de enxofre, nitrogênio e hidrogênio foram realizadas com amostras secas do lodo no equipamento TruSpec $\circledR$ Micro Elemental Series.

Conforme metodologia descrita por Telmo et al. (2010), o conteúdo de oxigênio é usualmente estabelecido como a diferença entre os sólidos voláteis e a soma das porcentagens de carbono, hidrogênio, nitrogênio e enxofre.

\section{Determinação de PCS e PCI}

Para o cálculo de PCS e PCI foram utilizadas as Equações 02 e 03, propostas por Rose e Cooper (1977), ideais para predições de poder calorífico em biomassa.

\section{$\mathrm{PCS}=\mathrm{C} \times \mathrm{PCS}_{\text {carbono }}+\mathrm{H} \times \mathrm{PCS}_{\text {hidrogênio }}$ (Equação 02) $\mathrm{PCI}=\mathrm{C} \times \mathrm{PCS}_{\text {carbono }}+\mathrm{H} \times \mathrm{PCI}_{\text {hidrogênio }}$ (Equação 03)}

Onde:

PCS = poder calorífico superior para cada lodo (MJ.kg-1)

$\mathrm{PCI}=$ poder calorífico inferior para cada lodo $\left(\mathrm{MJ} \cdot \mathrm{kg}^{-1}\right)$

$\mathrm{C}=$ concentração de carbono nas amostras (\%)

$\mathrm{H}=$ concentração de hidrogênio nas amostras (\%)

$\mathrm{PCS}_{\text {carbono }}=$ poder calorífico superior do carbono (MJ.kg-1)

$\mathrm{PCS}_{\text {hidrogênio }}=$ poder calorífico superior do hidrogênio $\left(\mathrm{MJ}^{\mathrm{kg}} \mathrm{kg}^{-1}\right)$

$\mathrm{PCI}_{\text {hidrogênio }}=$ poder calorífico inferior do hidrogênio $\left(\mathrm{MJ} \cdot \mathrm{kg}^{-1}\right)$

Os dados de PCS para o carbono e hidrogênio utilizados são tabelados: 34,02 MJ.kg-1e 141,85 MJ.kg-1, respectivamente. Já o PCI para o hidrogênio é de 119,81 MJ.kg-1. 0 carbono possui apenas PCS porque sua queima produz $\mathrm{CO}_{2}$. Para o hidrogênio, uma molécula de água pode ser produzida quando da queima (Kreith e Goswami, 2004).

\section{Balanço de energia}

0 balanço de energia foi feito através de equações da calorimetria para determinar a quantidade de calor necessária para evaporar toda a água presente nos lodos (reação endotérmica) e a quantidade de calor gerada na queima do lodo (exotérmica), através da utilização de PCI. As Equações 04 e 05 estão listadas a seguir:

\section{Qágua $=\mathrm{m}_{\text {água }} \mathrm{X}$ Cágua $\mathrm{X}(\Delta \mathrm{t})+\mathrm{m}_{\text {água }} \mathrm{X}$ Lágua $\quad$ (Equação 04) $\mathrm{Q}_{\text {lodo }}=$ mlodo $_{\text {lo }} \mathrm{PCI}$ \\ (Equação 05)}

Onde:

$\mathrm{Q}_{\text {água }}=$ calor necessário para evaporar toda a água do resíduo (MJ.kg-1)

$\mathrm{m}_{\text {água }}=$ umidade $(\% \mathrm{~m} / \mathrm{m})$

Cágua = calor específico da água $\left(0,004184 \mathrm{MJ} \cdot \mathrm{kg}^{-{ }^{\circ} \mathrm{C}} \mathrm{C}^{-1}\right)$

$\Delta \mathrm{t}=$ diferença de temperatura $\left(100^{\circ} \mathrm{C}\right.$ - temperatura ambiente $)$

$\mathrm{L}_{\text {água }}=$ calor latente de vaporização da água $\left(2,256 \mathrm{MJ} \cdot \mathrm{kg}^{-1}\right)$

$\mathrm{Q}_{\text {lodo }}=$ calor gerado pela queima do lodo $\left(\mathrm{MJ} \cdot \mathrm{kg}^{-1}\right)$

$\mathrm{m}_{\text {lodo }}=$ massa de lodo $(\% \mathrm{~m} / \mathrm{m})$

$\mathrm{PCI}=$ poder calorífico inferior de cada lodo $\left(\mathrm{MJ} \cdot \mathrm{kg}^{-1}\right)$ 
Foram utilizados dados históricos de três anos (2013, 2014 e 2015) de lodo gerado nas três indústrias para prever a quantidade de energia que pode ser gerada por ano.

\section{Análise estatística}

As médias de cada variável foram comparadas entre os três tipos de lodo através do teste de Tukey a 5\% de probabilidade, com o uso do programa estatístico Statistix $10^{\circledR}$. Os fatores de correlação de Pearson foram utilizados com o intuito de avaliar as possíveis associações entre os sólidos voláteis e os elementos presentes nos lodos.

\section{Resultados e discussão}

\section{das biomassas \\ Caracterização físico-química}

A Figura 1 traz os resultados encontrados para umidade, sólidos voláteis e sólidos fixos para os três tipos de lodo.

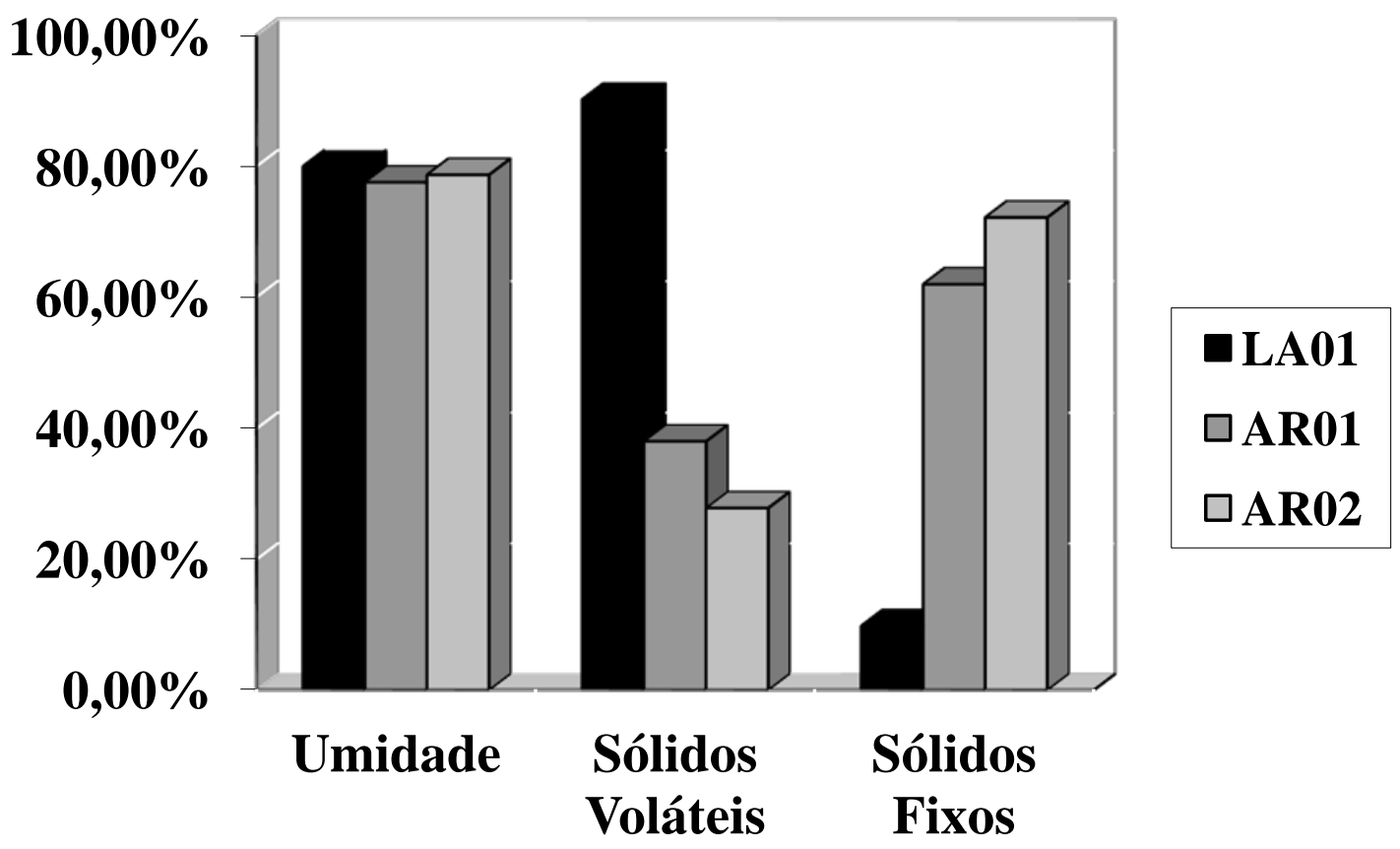

Figura 1. Percentuais de umidade $\left(\mathrm{m} \cdot \mathrm{m}^{-1}\right)$, sólidos voláteis $\left(\mathrm{m} \cdot \mathrm{m}^{-1}\right)$ e sólidos fixos $\left(\mathrm{m} \cdot \mathrm{m}^{-1}\right)$ nos três tipos de lodo estudados.

Houve diferença significativa na análise de umidade entre cada tipo de lodo. As três indústrias possuem sistemas de deságue de lodo. A indústria de laticínios possui um decanter centrífugo, que se mostrou menos eficiente para remoção de água do lodo descartado da ETE. As duas indústrias de arroz parboilizado possuem prensa desaguadora, a diferença entre elas é que a AR01 utiliza um polímero antes da entrada do lodo na prensa, o que aglutina os sólidos em flocos maiores, aumentando o teor de água livre, facilitando o deságue. Conforme McGhee (1991), os lodos contêm de 70\%-75\% de água livre, 20\%-25\% de água em flocos e $1 \%$ de umidade capilar. A água livre pode 
ser removida por espessamento; a água dos flocos através de desidratação mecânica; e a umidade capilar só pode ser removida por condicionamento químico, explicando a diferença entre os lodos de ETE de arroz parboilizado.

A umidade não é contabilizada como peso para o combustível porque ela diminui a efetividade de produção de calor, aumenta os custos de transporte e o volume dos tanques de armazenamento. Como a evaporação é um processo endotérmico, a umidade diminui o conteúdo de energia utilizável e a temperatura de combustão, além da qualidade e eficiência da combustão. Elevados conteúdos de umidade em combustíveis requerem altos tempos de residência para desidratação, o que implica em elevadas câmaras, afetando o desenvolvimento do sistema de combustão. Além disso, diminui a qualidade física dos combustíveis, especialmente a durabilidade de estoque (García et al., 2014b).

Para os sólidos voláteis e sólidos fixos também houve diferença significativa entre os diferentes tipos de lodo, onde destaca-se a amostra de lodo de ETE de indústria de laticínios, que possui $90,20 \%$ de sólidos voláteis, o que demonstra um alto teor em termos de combustíveis. Já as amostras de lodo de arroz parboilizado AR01 e AR02 contém mais da metade de sua composição (61,95\% e $72,26 \%$, respectivamente) de sólidos fixos, demonstrando que terá elevada geração de cinzas caso os mesmos sejam utilizados para geração de energia, fazendo com que haja uma preocupação maior quando da destinação final destes resíduos.

Os efluentes de laticínios são constituídos de uma mistura rica em carbono e nutrientes, que são retirados dos sistemas de tratamento como lodo no tratamento primário (flotador), ao contrário dos efluentes de arroz parboilizado, que possuem material em sua grande maioria solúvel, que são incorporados à biomassa dos microrganismos dos sistemas de tratamento anaeróbios e aeróbios e, posteriormente, descartados como lodo. Além disso, o lodo também é gerado pela precipitação química do fósforo por adição de sais inorgânicos ou pela absorção do fósforo pela biomassa (Faria et al., 2006; Fyfe et al., 2016). Portanto, a diferença nas quantidades de material orgânico entre os tipos de lodo se deve à constituição do efluente gerado. García et al. (2014a) relatam que um elevado conteúdo de material volátil faz com que a ignição seja facilitada a baixas temperaturas, implicando alta reatividade e enriquecendo o processo de combustão.

A Tabela 1 mostra as análises elementares de nitrogênio, hidrogênio, enxofre, carbono orgânico e oxigênio para os três tipos de lodo.

Tabela 1. Análises de elementos em lodos de ETE de laticínios e de arroz parboilizado.

\begin{tabular}{cccccc}
\hline & C orgânico (\%) & N (\%) & H (\%) & S (\%) & 0 (\%) \\
\hline LA01 & $51,4 \pm 0,6 \mathrm{a}$ & $2,45 \pm 0,01 \mathrm{a}$ & $1,80 \pm 0,06 \mathrm{~b}$ & $0,42 \pm 0,03 \mathrm{~b}$ & $31,6 \pm 0,9 \mathrm{a}$ \\
AR01 & $25,4 \pm 1,0 \mathrm{~b}$ & $1,21 \pm 0,03 \mathrm{~b}$ & $4,28 \pm 0,02 \mathrm{a}$ & $0,65 \pm 0,08 \mathrm{a}$ & $9,6 \pm 1,2 \mathrm{~b}$ \\
AR02 & $15,2 \pm 0,6 \mathrm{~b}$ & $1,22 \pm 0,04 \mathrm{~b}$ & $1,40 \pm 0,00 \mathrm{c}$ & $0,22 \pm 0,02 \mathrm{~b}$ & $9,9 \pm 1,0 \mathrm{~b}$ \\
\hline
\end{tabular}

A significância estatística entre os tipos de lodo foi calculada pelo teste de Tukey (p $\leq 0,05)$ e é representada por letras minúsculas nas colunas. Legenda: "C orgânico" - carbono orgânico; "N" nitrogênio; "H" - hidrogênio; "S" - enxofre; "O" - oxigênio.

Constata-se que o lodo LA01 possui uma quantidade percentual de carbono significativamente maior do que as amostras de lodo AR01 e AR02. 0 
efluente de laticínios possui uma elevada concentração de sólidos orgânicos dissolvidos, como proteínas, lactose, gorduras, minerais, sólidos lácteos, detergentes e sanitizantes e é caracterizado por possuir, portanto, elevada concentração de nutrientes e compostos orgânicos (Qasin e Mane, 2013). A retirada de grande parte deste material orgânico dá-se através de floculação. Como a indústria utiliza no tratamento primário um coagulante orgânico, constituído de unidades monoméricas do tipo flavan-3-ol, auxilia no incremento da geração de lodo com característica orgânica e não inorgânica, caso usasse outro tipo de coagulante (Mangrich et al., 2014).

Estudos mostram que o lodo de esgoto doméstico possui nitrogênio (variando entre $3,50 \%$ e $7,50 \%$ ) e enxofre (variando entre $1,00 \%$ e 1,50\%) em maior quantidade do que os lodos analisados, demonstrando uma vantagem no uso dos lodos industriais para obtenção de energia, que produzirão menos NOx e SOx, frente ao lodo de esgoto doméstico (Murakami et al., 2009; Werle e Wilk, 2010). As formas orgânicas de nitrogênio em lodos de laticínios de maior importância incluem produtos como aminoácidos, uréia, purinas e pirimidinas, demonstrando a maior concentração entre os lodos estudados (Mendonça et al., 2012). Em estudo com lodos de esgoto, os valores mais baixos aparecem mais correlacionados ao enxofre biogênico, levando à hipótese de que esses organismos poderiam se tratar de bactérias redutoras de sulfato presentes no tanque de lodo. 0 enxofre pode também estar mais correlacionado aos sulfatos insolúveis de chumbo e estrôncio, ou na forma elementar. 0 sulfato de alumínio utilizado no tratamento dos efluentes da AR01 como floculante também contribui para a presença deste elemento no lodo (Sigolo e Pinheiro, 2010).

Estudos comprovam que a faixa de concentração de oxigênio na biomassa seca de lodo de esgotos varia de 2,42\% a 43,47\% (Werle and Wilk, 2010). Este oxigênio pode ser proveniente de ligações $\mathrm{O}-\mathrm{H}$ de grupos funcionais de polissacarídeos, álcoois e ácidos, além do grupo $\mathrm{C}=\mathrm{O}$ presente em aldeídos, cetonas, ácidos carboxílicos, éteres e proteínas (Chan e Wang, 2016).

A Figura 2 mostra a correlação dos sólidos voláteis com os elementos oxidáveis presentes nos lodos estudados.

A correlação de Pearson entre os sólidos voláteis e os elementos carbono, oxigênio, hidrogênio, nitrogênio e enxofre foram $0,99,0,98,0,99,0,99$ e 0,11 , respectivamente. Nota-se que para os quatro primeiros elementos, as variáveis foram forte e positivamente correlacionadas linearmente, ou seja, se aumenta a concentração de sólidos voláteis no lodo, esses elementos também possuem a tendência de aumentar suas concentrações. Já para o enxofre e sólidos voláteis a correlação positiva foi fraca, e essa constatação indica serem as observações de certa forma não correlacionáveis e, sob a suposição de normalidade, independentes. 

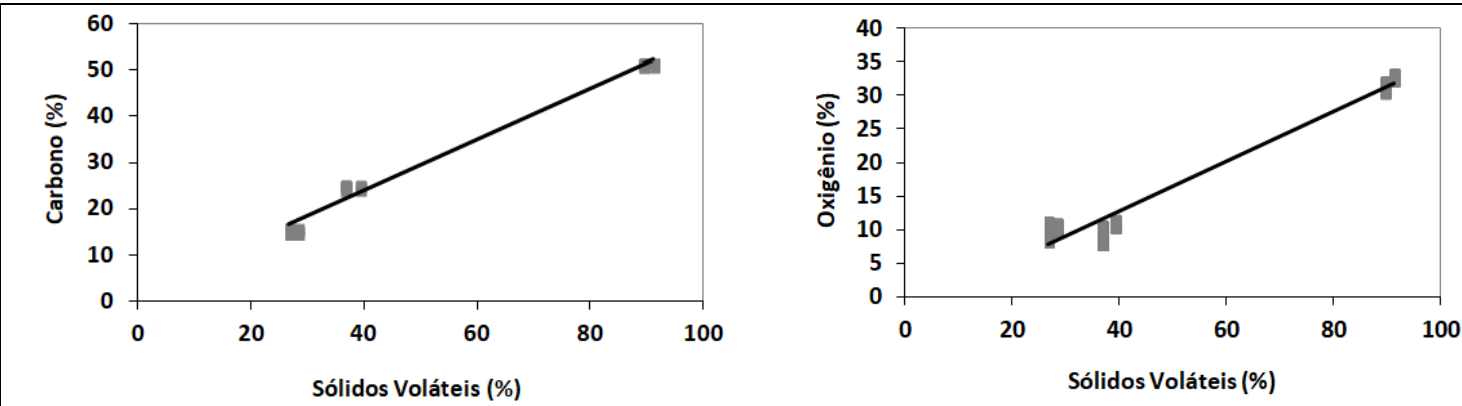

a

b
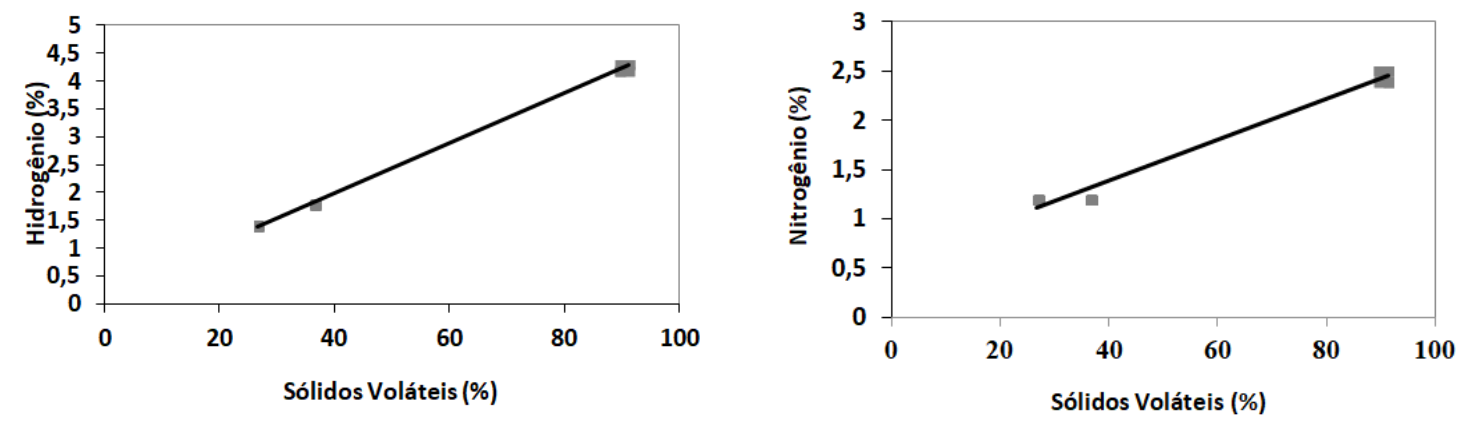

C

d

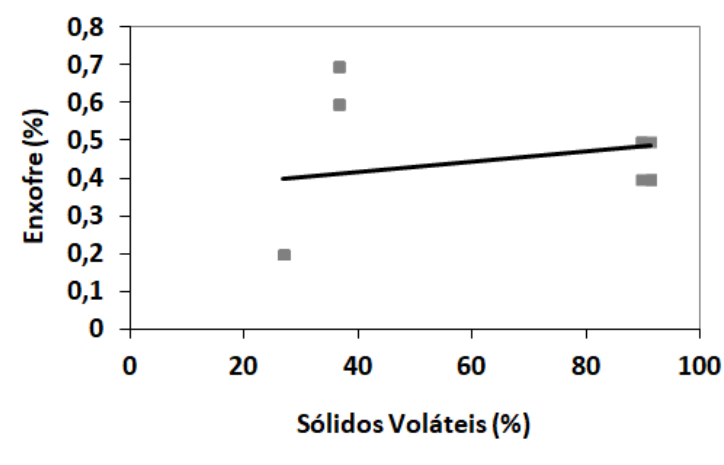

e

Figura 2. Correlação entre a concentração de sólidos voláteis e os elementos: a) carbono; b) oxigênio; c) hidrogênio; d) nitrogênio; e) enxofre.

Análise de PCS e PCI

A Tabela 2 mostra os valores calculados para PCS e PCI dos três tipos de lodos estudados. 
Tabela 2. Valores de Poder Calorífico Inferior (PCI) e Poder Calorífico Superior (PCS) nos lodos de ETE de laticínios e de arroz parboilizado.

\begin{tabular}{lcc}
\hline & PCI $\left({\left.\mathrm{MJ} . \mathrm{kg}^{-1}\right)}^{-1}\right.$ & PCS (MJ.kg-1) \\
\hline LA01 & $22,6 \pm 0,2 \mathrm{a}$ & $23,6 \pm 0,2 \mathrm{a}$ \\
AR01 & $10,8 \pm 0,8 \mathrm{~b}$ & $11,2 \pm 0,8 \mathrm{~b}$ \\
AR02 & $6,8 \pm 0,2 \mathrm{c}$ & $7,1 \pm 0,2 \mathrm{c}$ \\
\hline
\end{tabular}

A significância estatística entre os tipos de lodo foi calculada pelo teste de Tukey $(p \leq 0,05)$ e é representada por letras minúsculas nas colunas.

O PCS encontrado para os dois lodos de arrozeiras estão próximos de três indústrias analisadas por Thipkhunthod et al. (2005), que obtiveram valores de 10,9, 9,9 e $9,0 \mathrm{MJ} \cdot \mathrm{kg}^{-1}$. Isso foi observado devido à correspondência entre a baixa quantidade de material volátil e ao grande conteúdo de cinzas presentes no lodo, o que ocorreu neste estudo para os lodos AR 01 e AR02.

O lodo de ETE de laticínios obteve valor de PCS maior do que em muitos estudos de utilização de lodo de esgotos, que encontraram valores em torno de 20,1 MJ.kg-1 (Murakami et al., 2009).

0 PCS de lodo ativado possui 15 MJ.kg-1 em estudos de Werle e Wilk
(2010). Isso indica que a precipitação química utilizada nas arrozeiras aumenta a quantidade de sólidos fixos que influenciam negativamente no poder calorífico, ao contrário da flotação com produto orgânico na ETE de laticínios que, por sua vez, aumenta o poder calorífico deste tipo de lodo devido à maior presença de compostos orgânicos.

\section{Balanço de energia}

A Tabela 3 mostra a quantidade de energia necessária para evaporar toda a água do lodo (reação endotérmica Qágua), a quantidade de energia gerada pela queima do lodo seco (reação exotérmica - Q Qodo) e a variação de energia do processo $(\Delta Q)$.

Tabela 3. Balanço de energia para cada lodo estudado.

\begin{tabular}{lccc}
\hline & Qágua $\left(\mathrm{MJ} \cdot \mathrm{kg}^{-1}\right)$ & $\mathrm{Q}_{\text {lodo }}\left(\mathrm{MJ} \cdot \mathrm{kg}^{-1}\right)$ & $\Delta \mathrm{Q}\left(\mathrm{MJ}^{-1} \mathrm{~kg}^{-1}\right)$ \\
\hline LA01 & $2,05 \mathrm{a}$ & $4,52^{\mathrm{a}}$ & 2,47 \\
AR01 & $1,99 \mathrm{c}$ & $2,42 \mathrm{~b}$ & 0,43 \\
AR02 & $2,02 \mathrm{~b}$ & $1,46 \mathrm{c}$ & $-0,56$ \\
\hline
\end{tabular}

A significância estatística entre os tipos de lodo foi calculada pelo teste de Tukey $(p \leq 0,05)$ e é representada por letras minúsculas nas colunas.

A desidratação e a queima do lodo seco mostram um conteúdo de energia residual positivo para os lodos LA01 e AR01, enquanto não há recuperação energética (conteúdo de energia residual negativo) nestes processos para o lodo AR02, indicando que a operação de queima deste último lodo será útil caso a empresa queira diminuir o volume de resíduo a ser destinado. Estudos realizados com lodo de esgoto doméstico de cinco ETE em Cingapura, demonstram que o balanço de energia variou de $-1,91 \mathrm{MJ} . \mathrm{kg}^{-1}$ a 12,44 MJ.kg-1. São importantes aspectos a serem considerados para a sustentabilidade do processo a melhoria no processo de desidratação prévio e o 
potencial de reutilização do vapor de água gerado durante $\mathrm{o}$ processo de desidratação (Chan e Wang, 2016).

Para melhorar o desempenho da secagem dos lodos antes da queima, pode-se criar um sistema de aproveitamento do biogás (mistura de metano e dióxido de carbono) com coleta, armazenamento e queima em um sistema que recebe o lodo para desidratação, uma vez que as três ETE possuem reator UASB (reator anaeróbio de fluxo ascendente) que produz esta mistura de gases.

A Figura 3 mostra a quantidade de lodo descartado pelas indústrias, sem umidade, para os anos de 2013, 2014 e 2015.

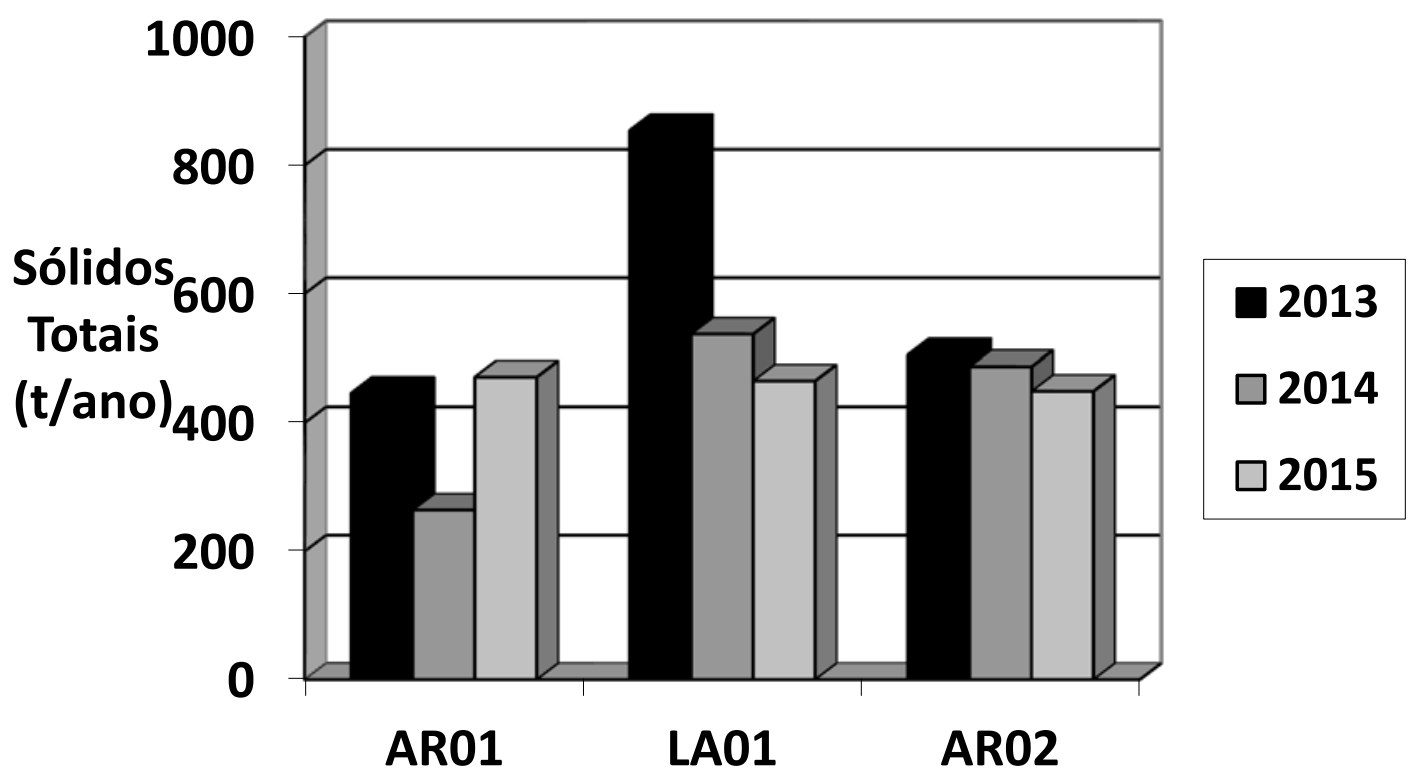

Figura 3. Massas de lodo LA01, AR01 e AR02 nos anos de 2013, 2014 e 2015, descontando a umidade.

Considerando-se a quantidade média destes combustíveis utilizados nas indústrias e os valores tabelados de poder calorífico para lenha (combustível utilizado na indústria de laticínios) e casca de arroz (combustível utilizado nas indústrias de arroz parboilizado), são, respectivamente, em média, $18,8 \mathrm{MJ} \cdot \mathrm{kg}^{-1}$ e 16,7 MJ.kg-1 (Quirino et al., 2005; Della et al., 2001), foi calculada a quantidade de dias que os atuais combustíveis das empresas seriam substituídos pelos lodos.
Analisando somente a massa seca dos lodos, ou seja, sem utilizar no balanço energético a energia necessária para remoção da umidade, os lodos LA01, AR01 e AR02 disponibilizam uma média de energia de $14 \mathrm{TJ}^{\mathrm{T} . \mathrm{ano}^{-1} \text {, }}$ 4 TJ.ano $^{-1}$ e 3 TJ.ano $^{-1}$, respectivamente. Essa energia disponível dos lodos substituiria 18 dias de uso de lenha na empresa de laticínios e cinco dias e quatro dias de substituição de casca de arroz nas indústrias que geram os lodos AR01 e AR02, respectivamente. Já 
considerando o balanço de energia, a utilização do lodo LA01 na queima em caldeira substituiria dois dias de uso de lenha por ano, enquanto o lodo AR01 substituiria 0,5 dias de uso de casca de arroz por ano. 0 lodo AR02 não foi analisado por não possuir recuperação energética.

Para o lodo AR02, infere-se que a troca do polímero utilizado antes da prensagem diminuirá a quantidade de água do lodo, através da retirada da umidade capilar, favorecendo o balanço energético e, possibilitando o uso deste lodo para a obtenção de energia de forma idêntica aos lodos provenientes das demais indústrias analisadas.

Confrontando os dados anuais de lodo úmido que está sendo transportado para áreas externas e as cinzas geradas no processo de queima, haverá uma redução considerável de peso. Ao passo que os lodos AR01 e AR02 diminuirão o seu peso em $86 \%$ e $85 \%$, respectivamente, o lodo LA01 diminuirá $98 \%$ de seu peso. Essa situação favorece o uso dos lodos em caldeiras de leito fluidizado, uma vez que a logística de transporte do resíduo final será diminuída.

Portanto, a geração destes lodos não é suficiente para manter a demanda de combustível para queima ao longo da operação das indústrias, pois não se produziria vapor suficiente para garantir a operacionalidade da malha energética das fábricas, mas podem ser utilizados como substitutos parciais das biomassas já utilizadas ou como incremento à matriz energética atual.

\section{Conclusões}

Conclui-se que foi possível determinar o poder calorífico dos três lodos estudados, que possuem valores condizentes com estudos realizados com lodos de esgotos domésticos e com lodos industriais, através de equações matemáticas. Os lodos LA01 e AR01 possuem balanço de energia positivo, sendo viáveis para aproveitamento na geração de energia para as indústrias.

A proposição de queima de lodo em caldeira se torna atrativa para a diminuição do volume de destinação destes resíduos para áreas externas às empresas, diminuindo custos operacionais como o de transporte. Observa-se a viabilidade do uso destes tipos de lodo em comparação com de outros estudos através de sua composição elementar, uma vez que possuem menos nitrogênio e enxofre que lodos de esgoto doméstico, o que diminui potencial risco de emissão de gases tóxicos à atmosfera.

\section{Conflito de interesses}

Os autores declaram não haver conflito de interesses.

\section{Referências}

ABNT - Associação Brasileira de Normas Técnicas. NBR 10.007-Amostragem de resíduos sólidos. Rio de Janeiro; ABNT, 2004.

APHA - American Public Health Association. Standard methods for the examination of water and wastewater. 22. ed. Washington, D. C.: American Public Health Association, 2012.

Borges, F.; Sellin, N.; Medeiros, S. H. W. Caracterização e avaliação de lodos de efluentes sanitário e industrial como biomassa na geração de energia. Ciência e Engenharia, v. 17, n. 1/2, p. 27-32, 2008. Disponível em: <http://www.seer.ufu.br/ index.php/cieng/article/view/730/5628>. Acesso em: $23 \mathrm{fev} .2018$.

Brasil. Lei no 12.305, de 02 de agosto de 2010. Institui a Política Nacional de Resíduos Sólidos; altera a Lei no 9.605, de 12 de fevereiro de 1998; e dá outras providências. Disponível em: <http://www.planalto.gov. br/ccivil_03/_Ato2007-2010/2010/Lei/ L12305.htm>. Acesso em: 23 fev. 2018.

Chan, W.P.; Wang, J. Comprehensive characterisation of sewage sludge for thermochemical conversion processes: Based on Singapore survey. Waste Management, 
v. 54, p. 131-142, 2016. https://doi.org/ 10.1016/j.wasman.2016.04.038

Della, V. P.; Kühn, I.; Hotza, D. Reciclagem de resíduos agro-industriais: cinza de casca de arroz como fonte alternativa de sílica. Cerâmica Industrial, v. 2 , n. 10 , p. 22-25, 2005. Disponível em: <http://www.ceramica industrial.org.br/pdf/v10n02/Publicado_v10 n2a03.pdf>. Acesso em: 23 fev. 2018.

Demirbas A. Toxic air emissions from biomass combustion. Energy Source, v. 25, n. 5 , p. 419-427, 2003. https://doi.org/ 10.1080/00908310390142433

Faria, O. L. V. F.; Koetz, P. R.; Santos, M. S.; Nunes, W. A. Remoção de fósforo de efluentes da parboilização de arroz por absorção biológica estimulada em reator em batelada sequencial (SBR). Ciência e Tecnologia de Alimentos, v. 26, n. 2, p. 309-317, 2006. https://doi.org/10.1590/S0101-20612006 000200013

Fyfe, J.; Hagare, D.; Sivakumar, M. Dairy shed effluent treatment and recycling: Effluent characteristics and performance. Journal of Environmental Management, v. 180, p. 133146, 2016. https://doi.org/10.1016/ j.jenvman.2016.04.058

Fytili, D.; Zabaniotou, A. Utilization of sewage sludge in EU application of old and new methods: A review. Renewable and Sustainable Energy Reviews, v. 12, n. 1, p. 116-140, 2008. https://doi.org/10.1016/ j.rser.2006.05.014

García, R.; Pizarro, C.; Lavín, A. G.; Bueno, J. L. Study of main combustion characteristics for biomass fuels used in boilers. Fuel Process Technology, v. 103, p. 16-26, 2012. https://doi.org/10.1016/j.fuproc.2011.12.03 2

García, R.; Pizarro, C.; Lavín, A. G.; Bueno, J. L. Spanish biofuels heating value estimation. Part I: Ultimate analysis data. Fuel, v. 117, Part B, p. 1130-1138, 2014a. https://doi.org/ 10.1016/j.fuel.2013.08.048

García, R.; Pizarro, C.; Lavín, A. G.; Bueno, J. L. Spanish biofuels heating value estimation. Part II: Proximate analysis data. Fuel, v. 117, Part B, p. 1139-1147, 2014b. https://doi.org/ 10.1016/j.fuel.2013.08.049

Jiménez, E. I.; García, V. P. Relationships between organic carbon and total organic matter in municipal solid wastes and city refuse composts. Bioresource Technology, v. 41 , p. 265-272, 1992 . https://doi.org/ 10.1016/0960-8524(92)90012-M
Khan, A. A.; Jonga, W. D.; Jansens, P. J.; Spliethoff, H. Biomass combustion in fluidized bed boilers: Potential problems and remedies. Fuel Process Technology, v. 90, n. 1 , p. 21-50, 2009. https://doi.org/ 10.1016/j.fuproc.2008.07.012

Kreith, F.; Goswami, D. Y. The CRC Handbook of Mechanical Engineering. 2. ed. New York: CRC Press, 2004.

Mangrich, A. S.; Doumer, M. E.; Mallmann, A. S.; Wolf, C. R. Química Verde no tratamento de águas: uso de coagulante derivado de tanino de Acacia mearnsii. Revista Virtual Química, v. 6, $\quad$ n.1, p. 2-15, 2014. https://doi.org/10.5935/1984-6835.2014 0002

McGhee, T. J. Water supply and sewerage. New York: McGraw-Hill, 1991.

Mendonça, H. V.; Ribeiro, C. B. M.; Borges, A. C.; Bastos, R. R. Remoção de nitrogênio e fósforo de águas residuárias de laticínios por sistemas alagados construídos operando em bateladas. Revista Ambiente \& Água, v. 7, n. 2 , p. 75-87, 2012. https://doi.org/ 10.4136/ambi-agua.805

Murakami, T.; Suzuki, Y.; Nagasawa, H.; Yamamoto, T.; Koseki, T.; Hirose, H.; Okamoto, S. Combustion characteristics of sewage sludge in an incineration plant for energy recovery. Fuel Processing Technology, v. 90, n. 6, p. 778-783, 2009. https://doi.org/10.1016/j.fuproc.2009.03.00 3

Qasim, W.; Mane, A. V. Characterization and treatment of selected food industrial effluents by coagulation and adsorption techniques. Water Resources and Industry, v. 4, p. 1-12, 2013. https://doi.org/10.1016/ j.wri.2013.09.005

Quirino, W. F.; Vale, A. T.; Andrade, A. P. A.; Abreu, V. L. S.; Azevedo, A. C. S. Poder calorífico da madeira e materiais lignocelulósicos. Revista da Madeira, v. 89, p. 100-106, 2005.

Rose, J. W., Cooper, J. R. Technical data on fuel. 7. ed. London: The British National Committee, World Energy Conference, 1977.

Shi, H.; Mahinpey, N.; Aqsha, A.; Silbermann, R. Characterization, thermochemical conversion studies, and heating value modeling of municipal solid waste. Waste Management, v. 48, p. 34-47, 2016. https://doi.org/10.1016/j.wasman.2015.09. 036 
Sigolo, J. B.; Pinheiro, C. H. R. Lodo de esgoto da ETE Barueri-SP: proveniência do enxofre elementar e correlações com metais pesados associados. Geologia USP, Série Científica, v. 10 , n. 1, p. 39-51, 2010. https://doi.org/ 10.5327/Z1519-874X2010000100004

Silva, R. C.; Marchi Neto, I.; Seifert, S. S. Electricity supply security and the future role of renewable energy sources in Brazil. Renewable and Sustainable Energy Reviews, v. 59, p. 328-341, 2016. https://doi.org/10.1016/j.rser.2016.01.001

Telmo, C.; Lousada, J.; Moreira, N. Proximate analysis, backwards stepwise regression between gross calorific value, ultimate and chemical analysis of wood. Bioresources Technology, v. 101, p. 3808-3015, 2010. https://doi.org/10.1016/j.biortech.2010.01. 021
Thipkhunthod, P.; Meeyoo, V.; Rangsunvigit, P.; Kitiyanan, B.; Siemanond, K.; Rirksomboon, T. Predicting the heating value of sewage sludges in Thailand from proximate and ultimate analyses. Fuel, n. 84, n. 7/8, p. 849-857, 2005. https://doi.org/ 10.1016/j.fuel.2005.01.003

Werle, S.; Wilk, R. K. A review of methods for the thermal utilization of sewage sludge: The Polish perspective. Renewable Energy, v. 35, p. 1914-1919, 2010. https://doi.org/ 10.1016/j.renene.2010.01.019

Werther, J.; Ogada, T. Sewage sludge combustion. Progress in Energy and Combustion Science, v. 25, n. 1, p. 55-116, 1999. https://doi.org/10.1016/S0360-1285 (98)00020-3 